\title{
Analisis Usahatani Sayuran Hidroponik di PT. Kusuma Agrowisata
}

\author{
Ekaria $^{1 凶}$ \\ ${ }^{1}$ Staf Pengajar Prodi AGRIBISNIS Fakultas Pertanian, Universitas Muhammadiyah Maluku Utara. Ternate. Indonesia, \\ Email : ekaria16@yahoo.com \\ Korespondensi : Ekaria, Universitas Muhammadiyah Maluku Utara, Ternate, Indonesia, \\ Email : ekaria16@yahoo.com
}

\begin{abstract}
ABSTRAK.
Penelitian ini bertujuan untuk mengetahui metode hidroponik yang dikembangkan di PT. Kusuma Agrowisata dan menganalisis usahatani sayuran hidroponik di PT. Kusuma Agrowisata. Metode analisis yang digunakan adalah analisis usahatani. Penelitian ini merupakan penelitian survei dengan pendekatan kualitatif deskriptif. Hasil penelitian menunjukkan bahwa usahatani sayuran hidroponik di PT. Kusuma Agrowisata menggunakan metode rakit apung (Floating Hydroponic Method) yang meliputi penggunaan media tanam, instalasi penanaman, nutrisi dan oksigen. Rata-rata produksi sayuran hidroponik di PT Kusuma Agrowisata yaitu 244,1 kg/musim tanam. Usahatani sayuran hidroponik di PT. Kusuma Agrowisata sangat menguntukan dan efisien. Teknologi yang digunakan cocok dengan budidaya sayuran untuk daerah perkotaan yang memiliki keterbatasan lahan.
\end{abstract}

\section{Keyword: Usahatani, Hidroponik, PT Kusuma Agrowisata}

\section{PENDAHULUAN}

\subsection{Latar Belakang}

Hidroponik merupakan salah satu alternatif yang dapat digunakan untuk meningkatkan produktivitas tanaman, terutama pada lahan sempit. Menurut Nazaruddin (1998), dengan adanya kemajuan teknologi pertanian memungkinkan penanaman sayuran di luar musimnya. Untuk itu, digunakan green house dan umumnya dilakukan dengan sistem hidroponik, sehingga kebutuhan akan sayuran dapat terpenuhi dan kontinyuitasnya dapat lebih terjaga. Hidroponik adalah istilah yang digunakan untuk menjelaskan tentang cara bercocok tanam tanpa menggunakan tanah sebagai media pertanamannya (Lingga, 2002).

Menurut Suhardiyanto (2002), beberapa kelebihan hidroponik dibandingkan dengan penanaman di media tanah antara lain adalah kebersihannya lebih mudah terjaga, tidak ada masalah berat seperti pengolahan tanah dan gulma, penggunaan pupuk dan air sangat efisien, tanaman dapat diusahakan terus tanpa tergantung musim, tanaman berproduksi dengan kualitas yang tinggi, produktivitas tanaman lebih tinggi, tanaman lebih mudah diseleksi dan dikontrol dengan baik dan dapat diusahakan di lahan yang sempit, terbebas dari penggunaan pestisida anorganik. Penggunaan pestisida anorganik ini dapat mencemari jaringan tanaman yang akan berakibat pula pada konsumen.

Dengan banyaknya kelebihan dari teknologi hidroponik juga kebutuhan masyarakat akan komoditas sayuran terus meningkat, maka terdapat peluang usaha di bidang pertanian dengan sistem hidroponik yang memiliki prospek menjanjikan. Sistem hidroponik dibagi menjadi tiga yaitu hidroponik substrak, NFT (Nutrient Film Technique), dan aeroponik. Tetapi sistem hidroponik substrat dan NFT yang paling banyak dikembangkan. Dalam pengembangannya bukan hanya untuk skala kecil tetapi sudah mencakup skala besar atau komersial, seperti yang sudah dikembangkan di PT. Kusuma Agrowisata.

Pengembangan usahatani sayuran hidroponik di PT. Kusuma Agrowisata menggunakan sistem hidroponik NFT (Nutrient Film Technique) dengan metode rakit apung (Floating Hydroponic Method).

Berdasarkan beberapa penelititan hidroponik yang telah dilakukan, menunjukkan bahwa sistem hidroponik NFT (Nutrient Film Technique) dengan metode rakit apung (Floating Hydroponic Method). Produksinya sangat stabil dan serangan hama tanaman dapat diminimalir. Menurut hasil penelitian 
Mas'ud (2009), nutrisi dan media tanam yang berbeda memberikan hasil yang berbeda terhadap pertumbuhan dan hasil tanaman selada. Azizah (2009), dalam penelitiannya menyimpulkan bahwa perlakuan antara media tanam dengan jenis pupuk berpengaruh sangat nyata terhadap semua variabel pertumbuhan dan perkembangan tanaman tomat. Pupuk dalam istilah hidroponik disebut juga dengan nutrisi. Nutrisi yang diperlukan tanaman meliputi unsur hara makro dan mikro. Setiap jenis nutrisi hidroponik memiliki komposisi yang berbeda-beda.

\subsection{Tujuan dan Manfaat Penelitian}

Penelitian ini bertujuan untuk mengetahui metode dan menganalisis usahatani sayuran hidroponik yang dikembangkan di PT. Kusuma Agrowisata, sedangkan manfaat penelitian ini adalah sebagai bahan informasi bagi petani dan masyarakat tentang metode usahatani sayuran hidroponik yang bisa dikembangkan pada lahan sempit atau pekarangan dan bahan informasi serta referensi bagi PT. Kusuma Agrowisata dalam pengembangan usaha.

\section{METODE PENELITIAN}

\subsection{Subjek, Objek dan Tempat Penelitian}

Pemilihan lokasi dilakukan secara sengaja (purposive) dengan pertimbangan bahwa PT Kusuma Agrowisata merupakan perusahaan yang memproduksi sayuran hidroponik dan konsisten di Jawa Timur.

\subsection{Analisis Usahatani}

Untuk menganalisis usahatani sayuran hidroponik di PT Kusuma Agrowisata, akan di analisis secara deskriptif kuantitatif yang berkaitan dengan teknik budidaya, faktor produksi, biaya, pendapatan dan efisiensi usahatani. Menurut Soekartawi (1995), untuk menghitung total biaya produksi dapat dihitung dengan rumus :

$$
\mathrm{TC}=\mathrm{FC}+\mathrm{VC}
$$

Keterangan :

$\mathrm{TC}=$ Total biaya $(\mathrm{Rp})$

$\mathrm{FC}=$ Biaya tetap $(\mathrm{Rp})$

$\mathrm{VC}=$ Biaya variabel $(\mathrm{Rp})$

Untuk menghitung besarnya penerimaan usahatani dapat dihitung dengan rumus :

$$
\mathrm{TR}=\mathrm{Y} \text {. Py }
$$

Keterangan :

$\mathrm{TR}=$ Total penerimaan $(\mathrm{Rp})$

$\mathrm{Y}=$ Jumlah produksi

Py = Harga jual produk

Keuntungan dari usahatani yang telah dilakukan dihitung dengan menggunakan rumus (Soekartawai, 1995) :

$$
\pi=\mathrm{TR}-\mathrm{TC}=\mathrm{Y} \cdot \mathrm{Py}-\left(\sum \mathrm{Xi} . \mathrm{Pxi}\right)-\mathrm{BTT}
$$

Dimana : $\mathrm{TR}=\mathrm{Y}$. Py

Keterangan :

$$
\mathrm{TC}=(\mathrm{Xi} . \text { Pxi })-\mathrm{BTT}
$$

$$
\begin{aligned}
& \pi=\text { Keuntungan (Rp) } \\
& \text { TR = Penerimaan (Rp) } \\
& \text { TC = Biaya Total (Rp) } \\
& \text { Y = Hasil produksi }(\mathrm{kg}) \\
& \text { Py = Harga satuan produksi (Rp) } \\
& \text { Xi = Faktor produksi } \\
& \text { Pxi = Harga faktor produksi (Rp/satuan) } \\
& \text { BTT = Biaya tetap modal (Rp) } \\
& \text { i } \quad=1,2,3,4,5, \ldots \mathrm{n}
\end{aligned}
$$

Untuk mengetahui efisiensi usahatani sayuran hidroponik digunakan analisis Return Cost of Ratio (RCR) dengan rumus menurut Hernanto (1991) :

$$
\mathrm{RCR}=\frac{\mathrm{TR}}{\mathrm{TC}}
$$


Keterangan :

RCR = Rasio pengembalian biaya

$\mathrm{TR}=$ Total penerimaan (total revenue)

$\mathrm{TC}=$ Total biaya poduksi (total cost)

Berdasarkan nilai tersebut, maka kriteria pengukurannya sebagai berikut :

a. Jika RCR $>1$, Usahatani menguntungkan secara ekonomis.

b. Jika $\mathrm{RCR}=1$, maka usahatani berada pada titik impas (break even point) yaitu keadaan dimana penerimaan sama dengan biaya total yang dikeluarkan.

c. Jika RCR $<1$, maka usahatani tidak menguntungkan secara ekonomis, karena penerimaan lebih kecil dari pada biaya total yang dikeluarkan.

\subsection{Operasional Variabel}

1. Produksi sayuran hidroponik ialah jumlah output atau hasil panen sayuran hidroponik dari luas lahan selama satu kali musim tanam.

2. Biaya produksi ialah seluruh biaya yang dikeluarkan dalam kegiatan usahatani sayuran hidroponik dalam satu kali musim tanam yang terdiri dari biaya tetap dan biaya variabel.

3. Biaya total ialah total dari biaya tetap dan biaya variabel.

4. Biaya tetap ialah biaya yang harus dikeluarkan dalam berusahatani yang besar kecilnya tidak tergantung pada volume produksi.

5. Biaya variabel ialah biaya yang besar kecilnya akan berpengaruh secara langsung dengan jumlah produksi.

6. Harga input ialah harga input faktor-faktor produksi, seperti sarana produksi dan peralatan pertanian yang harus dibayar oleh petani.

7. Harga produk ialah nilai tukar produk dalam satu kali musim tanam.

8. Penerimaan ialah uang yang diterima dari jumlah produksi yang dihasilkan untuk satu kali musim tanam dikalikan dengan harga produk per kg ditingkat petani.

9. Keuntungan ialah penerimaan usahatani dikurangi dengan biaya total (biaya tetap dan biaya variabel) yang dikeluarkan selama proses produksi dalam satu kali tanam.

10. Luas greenhouse ialah luas areal usahatani sayuran hidroponik yang digunakan dalam berusahatani.

11. Nutrisi ialah banyaknya unsur hara yang digunakan dalam usahatani sayuran hidroponik.

12. Tenaga kerja ialah banyaknya tenaga kerja yang tercurahkan dalam proses produksi sampai panen dalam satu kali musim tanam.

\section{HASIL DAN PEMBAHASAN}

\subsection{Metode Hidroponik yang dikembangkan di PT. Kusuma Agrowisata}

PT. Kusuma Agrowisata dalam pengembangan usahatani sayuran hidroponik menggunakan metode rakit apung (Floating Hydroponik Method) karena media tanam yang digunakan mudah didapat dan instalasi tanaman setelah panen mudah dibersihkan. Sehingga serangan hama penyakit bisa diatasi dan dapat meningkatkan produksi usahatani sayuran hidroponik.

Metode hidroponik rakit apung (Floating Hydroponik Method) yang dikembangkan di PT. Kusuma Agrowisata merupakan salah satu metode penanaman yang dilakukan dengan meletakkan tanaman pada lubang styrofoam yang mengapung di atas permukaan larutan nutrisi. Larutan nutrisi akan berada pada suatu bak yang digunakan sebagai media, kemudian tanaman yang akan ditanam diletakkan pada media tersebut. Prinsip dasar bertanam secara hidroponik rakit apung adalah dengan menempatkan tanaman terapung tepat berada di atas cairan nutrisi. Kelebihan dari metode ini adalah tanaman akan mendapatkan pasokan air dan juga nutrisi secara rutin, sehingga bisa memudahkan perawatan. Metode hidroponik rakit apung dapat dilihat pada Gambar 1.

Unsur-unsur dalam metode hidroponik rakit apung (Floating Hydroponik Method) yaitu :

\subsubsection{Media Tanam}

Media tanam yang digunakan yaitu spons dan stryofoam. Rongga udara pada spons harus terisi oleh air agar spons jenuh air yang ditunjukkan pada penampakan kuning gelap dan spons tidak jenuh air menjadi kuning terang. Spon jenuh air adalah keadaan yang baik agar benih/ biji berkecambah. Untuk persemaian memerlukan tray plastik dan spons yang sudah jenuh air dan berukuran $2,5 \times 2,5 \times$ 
2,5 cm dengan bagian tengahnya disayat bersinggungan. Kemudian spons diletakkan berjajar hingga memenuhi tray plastik. Benih diletakkan di bagian tengah spons yang disayat dengan menggunakan alat bantu pinset. Tray plastik yang sudah terisi benih diletakkan pada rak persemaian kemudian digelapkan dengan cara ditutup kain hitam untuk merangsang pertumbuhannya. Setelah 5-7 hari bibit siap dipindahkan pada lubang-lubang stryfoam yang berlubang dengan spesifikasi panjang $80 \mathrm{~cm}$, lebar $55 \mathrm{~cm}$, diameter lubang $2 \mathrm{~cm}$ dan jarak antar lubang 7 x $8 \mathrm{~cm}$. Sebelum tanaman dipindahkan sebaiknya diadaptasikan terlebih dahulu dengan cara dikenakan sinar matahari.

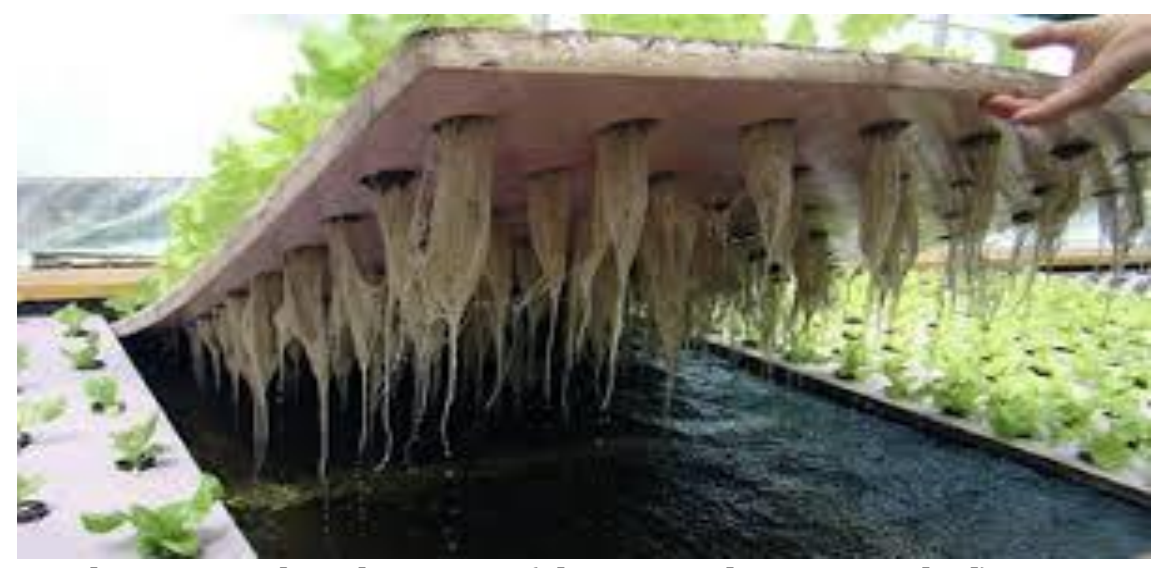

Gambar 1. Metode Rakit Apung (Floating Hydroponic Method)

\subsubsection{Instalasi Tanaman}

Instalasi tanaman menggunakan bak fiber yang berukuran $26 \times 0,6 \mathrm{~m}$ yang digunakan sebagai tempat air bernutrisi sekaligus untuk menyangga styrofoam. Dalam 1 greenhouse dengan luas $30 \times 3$ $m$ terdapat 4 bak fiber yang tersusun menjadi 2 tingkat dengan jumlah titik tanam sebanyak 7.144.

\subsubsection{Nutrisi}

Nutrisi yang digunakan merupakan formulasi yang dibuat langsung terdiri dari unsur hara makro dan mikro yang dibutuhkan tanaman. Satu greenhouse membutuhkan 20 liter nutrisi yang sudah dicampurkan dengan 6.000 liter air untuk 1 kali produksi.

\subsubsection{Oksigen}

Pemberian oksigen dilakukan dengan menggunakan pompa air lux pompa semi jet 100 watt dengan daya hisap $11 \mathrm{~m}$ (max). Selain untuk pemberian oksigen pompa air digunakan untuk mengalirkan dan mendorong air. Pompa air yang dipilih harus sesuai dengan model instalasi sehingga nutrisi dapat tersikulasi dengan baik. Daya listriknya 100 watt dan dijalankan dari jam 07.00-15.00, kemudian pada jam berikutnnya dijalan setaiap 1 jam dengan menggunakan timer.

\subsubsection{Perawatan Tanaman}

Perawatan yang dilakukan yaitu pengecekan kandungan nutrisi dalam bak penampung air, pengecekan $\mathrm{Ph}$ air, pembersihan bak penampung air untuk menghindari bakteri yang dapat mengganggu tanaman sayuran hidroponik dan seleksi tanaman yang terkontaminasi oleh penyakit agar tidak menular ke tanaman yang lain.

\subsection{Biaya Produksi, Pendapatan dan Efisiensi Usahatani Sayuran Hidroponik di PT. Kusuma Agrowisata}

Biaya usahatani atau biaya produksi merupakan pengeluaran yang harus dikeluarkan untuk memperoleh sarana produksi yang diperlukan. Biaya produksi yang dimaksud adalah seluruh biaya yang dikeluarkan baik yang bersifat tunai dan berdasarkan pertimbangan. Biaya produksi dapat dikelompokkan atas biaya tetap dan biaya variabel. Biaya tetap merupakan biaya produksi yang jumlah dan jenisnya tidak berubah dalam satu kali musim tanam walaupun jenis produksi yang dihasilkan tidak sama. Biaya variabel merupakan biaya yang dapat berubah besar kecilnya dalam satu kali musim tanam.

Secara terperinci biaya investasi yang dikeluarkan dalam pengembangan usahatani sayuran hidroponik di PT. Kusuma Agrowisata dan Puspa Agro pada Tabel 1. Tabel 1, Menunjukkan biaya investasi terbesar yaitu pembuatan greenhouse dan instalasi tanaman. Biaya investasi untuk pembuatan 
greenhouse dan instalasi tanaman sebesar Rp 100.000.000/greenhouse dengan luas 30 x 3 m sehingga total luas keseluruhan 6 unit greenhouse yaitu $540 \mathrm{~m}^{2}$ dan biaya investasi greenhouse dan instalasi tanaman sebesar $\mathrm{Rp}$ 600.000.000. Biaya penyusutan sebesar Rp 23.662.014. Kerangka greenhouse dan instalasi tanaman terbuat dari besi sehingga biaya investasi yang dikeluarkan cukup besar.

Selain biaya tetap yang dikeluarkan dalam usahatani sayuran hidroponik terdapat biaya variabel yang meliputi pembelian sarana produksi dan upah tenaga kerja. Tenaga kerja meliputi tenaga kerja untuk budidaya, perawatan, panen, dan pengemasan. Secara terperinci biaya produksi usahatani sayuran hidroponik di PT. Kusuma Agrowisata pada Tabel 2.

Tabel 1. Biaya Investasi Usahatani Sayuran Hidroponik di PT. Kusuma Agrowisata

\begin{tabular}{rlrrr}
\hline No & \multicolumn{1}{c}{ Jenis Alat } & $\begin{array}{c}\text { Jumlah } \\
\text { (Unit) }\end{array}$ & $\begin{array}{c}\text { Harga Satuan } \\
\text { (Rp/Unit) }\end{array}$ & \multicolumn{1}{c}{\begin{tabular}{c}
\multicolumn{1}{c}{ Total } \\
(Rp)
\end{tabular}} \\
\hline 1 & Greenhouse daninstalasitanaman & 6 & 100.000 .000 & 600.000 .000 \\
2 & Pompaaquarium(250 watt) & 6 & 500.000 & 3.000 .000 \\
3 & Nampan & 102 & 5.000 & 51.000 \\
4 & Pisau & 4 & 5.000 & 20.000 \\
5 & Pinset & 4 & 5.000 & 20.000 \\
6 & TDS dan AC & 1 & 150.000 & 150.000 \\
7 & Phmeter & 1 & 150.000 & 150.000 \\
\hline & Total & & & $\mathbf{6 0 3 . 3 9 1 . 0 0 0}$ \\
& Penyusutan & & & $\mathbf{2 3 . 6 6 2 . 0 1 4}$ \\
\hline
\end{tabular}

Sumber : PT. Kusuma Agrowisata, 2018

Tabel 2. Biaya Produksi Usahatani Sayuran Hidroponik di PT Kusuma Agrowisata/ Musim Tanam (40 Hari)

\begin{tabular}{lr}
\hline \multicolumn{1}{c}{ Uraian } & Rp \\
\hline Benih & 155.000 \\
Listrik & 300.000 \\
Air & 1.200 .000 \\
Spons & 368.000 \\
Nutrisi & 900.000 \\
Pengemasan & 922.000 \\
Tenaga Kerja & 6.000 .000 \\
Penyusutan & 23.662 .000 \\
Total Biaya & 33.662 .000 \\
Penerimaan & 51.982 .000 \\
Keuntungan & 18.320 .000 \\
RCR & 1,33 \\
\hline
\end{tabular}

Sumber : PT. Kusuma Agrowisata, 2018

Produksi setiap musim tanam berbeda produksi tertinggi berada dimusim tanam ke IV yaitu $1.521 \mathrm{~kg}$. Rata-rata produksi sayuran hidroponik di PT. Kusuma Agrowista yaitu $1485 \mathrm{~kg}$ dengan harga jual yang sama setiap musim tanam yaitu Rp. 35.000. hal ini menunjukkan produksi sayuran hidroponik di PT. Kusuma Agrowisata sangat stabil sehingga dapat memenuhi permintaan konsumen. Secara terperinci produksi dan harga jual sayuran hidroponik di PT. Kusuma Agrowisata dapat dilihat pada tabel 3.

Tabel 3. Produksi dan Harga Jual Sayuran Hidroponik di PT Kusuma Agrowisata

\begin{tabular}{cccc}
\hline $\begin{array}{c}\text { Musim } \\
\text { Tanam }\end{array}$ & $\begin{array}{c}\text { Produksi } \\
\text { (Kg) }\end{array}$ & $\begin{array}{c}\text { Rarga Jual } \\
\text { (Rp/Kg) }\end{array}$ & $\begin{array}{c}\text { Penerimaan } \\
\text { (Rp) }\end{array}$ \\
\hline I & 1.464 & 35.000 & 51.240 .000 \\
II & 1.471 & 35.000 & 51.485 .000 \\
III & 1.475 & 35.000 & 51.625 .000 \\
IV & 1.521 & 35.000 & 53.235 .000 \\
V & 1.495 & 35.000 & 52.325 .000 \\
\hline Total & 7.426 & & 259.910 .000 \\
Rata-rata & 1.485 & & 51.982 .000 \\
\hline
\end{tabular}

Sumber : PT. Kusuma Agrowisata, 2018 


\section{PENUTUP}

\subsection{Kesimpulan}

1. Metode usahatani sayuran hidroponik di PT. Kusuma Agrowisata menggunakan metode rakit apung yang meliputi media tanam dari spon dan styrofoam, instalasi penanaman berupa bak fiber sebagai tempat larutan nutrisi, nutrisi yang digunakan merupakan hasil formulasi sendiri dan oksigen sebagai sirkulasi udara. Terdapat perbedaan yang signifikan usahatani sayuran hidroponik yang dikembangkan di PT. Kusuma Agrowisata dan Puspa Agro.

2. Usahatani sayuran hidroponik di PT. Kusuma Agrowisata sangat menguntukan dan efisien dengan nilai RCR 1,33.

\subsection{Saran}

1. Perlu adanya bimbingan dan pelatihan karyawan atau tenaga kerja secara berkala sehingga dapat meningkatkan kinerja karyawan di perusahaan.

2. Perlu adanya penelitian lebih lanjut yang menganalisis penilaian tingkat risiko pada kegiatan spesialisasi dan diversifikasi.

\section{DAFTAR PUSTAKA}

Azizah, U.N. 2009. Pengaruh Media Tanam dan Jenis Pupuk terhadap Pertumbuhan dan Perkembangan Tanaman Tomat (Lycopersium esculentum Mill) denga Teknik Budidaya Hidroponik. Universitas Islam Maulana Malik Ibrahim. Malang.

Alviani, P. 2015. Bertanam Hidroponik Untuk Pemula. Depok : Bibit Publisher.

Arikunto, S. 2007. Manajemen Penelitian. Jakarta : Rineka Cipta.

Debertin, D.L. 1986. Agricultural Production Economics. Macmillan Publishing Company, New York.

Ellis, F. 1998. Peasant Economics : Farm Household and Agricultural Development. Cambridge University Press, Cambridge.

Ellton, G. 1995. Modern Portfolio Theory and Investment Analysis Fifth Edition. New York: John Wiley and Sons, Inc.

Henderson, JM. And Quandt, RE. 1980. Microeconomics Theory. A Mathematical Approach. Third Edition. McGraw Hill International Book Company, Tokyo.

Heyer, J. 1972. An Analysis of Peasant Farm Production. American J. Agric. Econ. (76) : 1107-1113.

Kennedy OS. And EM Fransisco. (1974). On The Formulation of Risk Constraint for Linier Programming. J. Agric. Econ. 25 (2) : 129-145.

Lingga P. 2005. Hidroponik Bercocok Tanam Tanpa Tanah. Jakarta : Penebar Swadaya.

Mas'ud, H. 2009. Sistem Hidroponik dengan Nutrisi dan Media Tanam Berbeda terhadap Pertumbuhan dan Hasil Selada. Program Studi Budidaya Pertanian. Fakultas Pertanian. Universitas Tadulako. Palu.

Nazaruddin. 1998. Budidaya dan Pengaturan Panen Sayuran Dataran Rendah. Jakarta : Penebar Swadaya.

Noor, J. 2011. Metodologi Penelitian: Skripsi, Tesis, Disertasi, dan Karya Ilmiah. Jakarta : Kencana.

Perwtasari, A. 2012. Pengaruh Media Tanam dan Nutrisi Terhadap Pertumbuhan dan Hasil Tanaman Pakchoi (Brassica juncea L.) dengan Sistem Hidroponik. Jurnal Agrovigor, Volume 5 No.1 Maret 2012.

Resh. HM. Ph.D. 2004. Hydroponic Food Production. Sixth edition. New Jersey : New Concept Press.

Roidah. 2014. Pemanfaatan Lahan Dengan Menggunakan Sistem Hidroponik. Jurnal Universitas Tulungagung Bonorowo, Volume 1 No. 2.

Sameto H. 2003. Hidroponik Sederhana Penyejuk Ruangan. Jakarta : Penebar Swadaya.

Siregar, S. 2015. Statistika Terapan. Jakarta : Prenadamedia Group.

Sudarmodjo. 2011. Hidroponik. Parung: Parung Farm

Sutiyoso, Y. 2004. Hidroponik ala Yos. Jakarta : Penebar Swadaya.

Suhardiyanto. 2002. Bercocok Tanam Hidroponik. Jakarta : Swadaya

Shinta, A. 2011. Ilmu Usahatani. Malang : UB Press.

Suratiyah, K. 2009. Ilmu Usahatani. Penebar Swadaya. Jakarta.

Sugiyono. 2006. Metode Penelitian Bisnis. Salemba Empat, Jakarta. 